\section{Upper Full Rehabilitation with One to One Immediate Loading Implants: A Case Report}

\author{
Maurizio Serafini ${ }^{1 *}$, Sara Di Teodoro ${ }^{1}$, Luisa Romondio ${ }^{1}$ and \\ Luigi Zagaria ${ }^{2}$ \\ ${ }^{1}$ Private Practitioner, Via Caduti Sul Lavoro, 37 - 66100 Chieti, Italy \\ ${ }^{2}$ Professor, Bari's University, Italy
}

\begin{abstract}
The purpose of this clinical case report is to describe a full-arch rehabilitation with one to one endosseous implant restoration.

Although the proposed treatment may not be within the financial means of most patients, the aesthetical result is higher because of the close similarity between the final restorations and the natural dentition.
\end{abstract}

The following case demonstrates how dentistry can change patients lives by rehabilitating them with immediate load implants and restore their smiles.

Keywords: Bone Regeneration; C.S.L. 2s implant; Dental implants; Growth factors; One to one immediate loading implants; Oral rehabilitation

\section{Introduction}

One to one immediate load implants allows the maintenance of a perfect balanced ratio between the edentulous space and the number of implants inserted, so that load forces can be better dissipate on a wider cancellous and cortical bone area.

Immediate loading implantology allows to place titanium dental implants and prosthesis on the same day or within $24 / 48$ hours from surgery [1].

Bone evaluation needs to be done prior to surgery and if the bone is not adequate, bone grafting is required. Immediate load offers many advantages, first of all significantly decreasing treatment time and trauma for the patient, increasing aesthetic and functional benefits.

${ }^{\overline{ }}$ Corresponding author: Maurizio Serafini, Private Practitioner, Via Caduti Sul Lavoro, 37 - 66100 Chieti, Italy, E-mail: serafinidrmaurizio@gmail.com

Citation: Serafini M, Teodoro SD, Romondio L, Zagaria L (2021) Upper Full Rehabilitation with One to One Immediate Loading Implants: A Case Report. J Stem Cell Res Dev Ther 7: 084.

Received: October 15, 2021; Accepted: November 01, 2021; Published: November 07, 2021

Copyright: (C) 2021 Serafini M, et al. This is an open-access article distributed under the terms of the Creative Commons Attribution License, which permits unrestricted use, distribution, and reproduction in any medium, provided the original author and source are credited.
This treatment option is becoming increasingly favored, thanks to researchers and manufacturers collaboration and their work on mechanical properties, implants chemical- physical structure and on histological bone/implant interactions [2].

When rehabilitating a patient, one of the most important things to evaluate is the occlusion, which has to be accurately examined to avoid implant fractures or failures due to overload. Neuromuscular occlusion is shaped by muscular and proprioceptive informations and when occlusal loads are transferred trough the prosthesis on each abutment, forces can be dissipated evenly.

One to one dental implants allows an easier cleaning maintenance by patients and has an esthetical outcome similar to natural teeth.

This can be achieved with proper healing of soft tissues trough mucogingival conditionment [3]

The pioneers who started immediate loading implants technique in Italy were: S. Tramonte, D. Garbaccio, Pierazzini, U. Pasqualini, G. Muratori, S. Lobello, A. Morra Greco, N. Marini, M. S. Formiggini; in The U.S.A. Were: L. Linkow, A. J. Viscido, L. C. Ward, Lew, Weiss and many others in Europe.

For the past 50 years, dental science has made huge progress not only on the material used (tantalium or steel) but also on the implant surface which was only machined back then and it was necessary to interconnect all implants with an electro-welded bar to gain stability.

The implants used in the current case are root-form, self-tapered and have incremental deep and thick spires in an apical-coronal direction, which allow forces dissipation and optimal primary stability. If forces are divided in many vectors, they can be better absorbed by cancellous bone and broken down in turn until they fade away in the cortical bone. This process is different for the cylindrical implant in which forces are dissipated on its last spire.

The implants used in the current paper can be inserted in every bone density (D1 to D4) since they determine both vertically and horizontally bone condensation while penetrating, obtaining great primary stability.

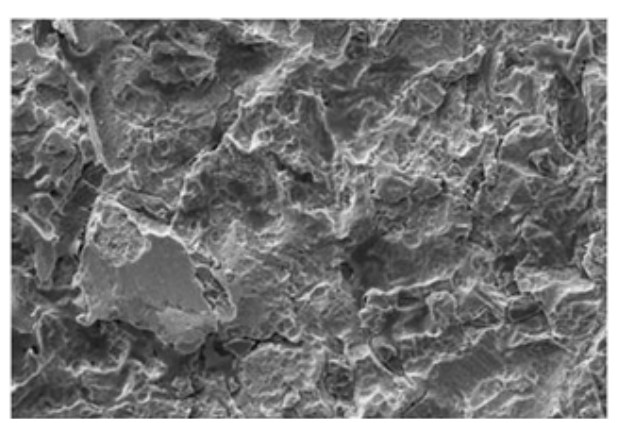

Figure 1: Implant Surface SEM Figure at 20 nano micron. 
Citation: Serafini M, Teodoro SD, Romondio L, Zagaria L (2021) Upper Full Rehabilitation with One to One Immediate Loading Implants: A Case Report. J Stem Cell Res Dev Ther 7: 084.

Also, it has tapered conic neck, which allows a greater volume between two adjacent implants: a bigger biological surface implies a better vascularization of the papilla.

Implant surface undergoes sandblasting and double etching treatment so to form pores from 0,5 to 20-40 micron, with high Bone Implants Contact (BIC) (Figures 1 \& 2)

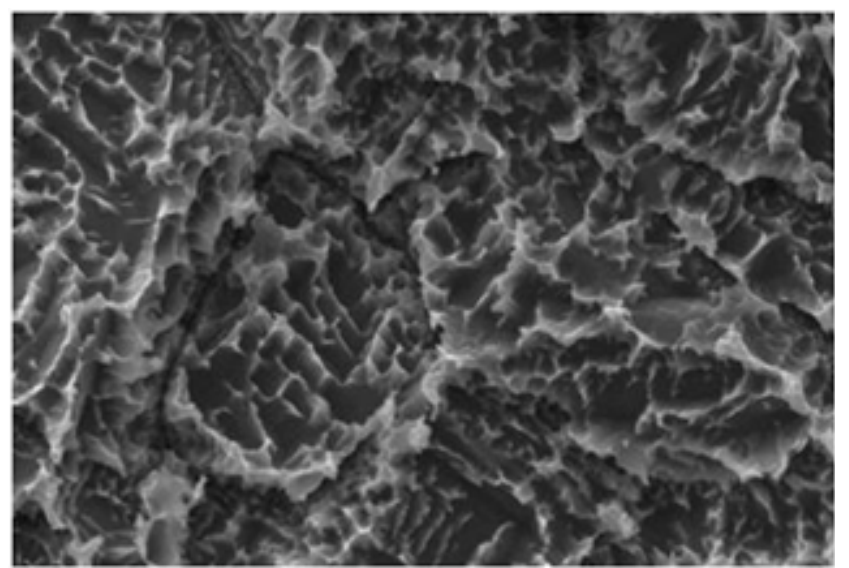

Figure 2: Implant Surface SEM figrure at 1 nano micron.

Wettability after all these procedures is high, the blood coat can easily stick on the surface and create fibrin net adhesion and promote osteogenesis by contact.

Last researches have also recurred to nano technology trough Discrete Crystalline Deposition (DCD) of Calcium Phosphate (CAP) nanoparticles that superimpose a nanotopographic complexity on each implant surface [4].

In order to use immediate loading implants, the primary stability has to be optimal because it is at first a mechanical phenomenon, but whit the progressive bone remodeling bone cells colonize the rough surface of the implants creating osteointegration.

This is the reason why immediate loading implantology it's not always possible but it requires bone quality and quantity standards.

If those standards are not satisfied, like in the case reported in figures 3 and 4, two stages surgery implantology is the valid alternative

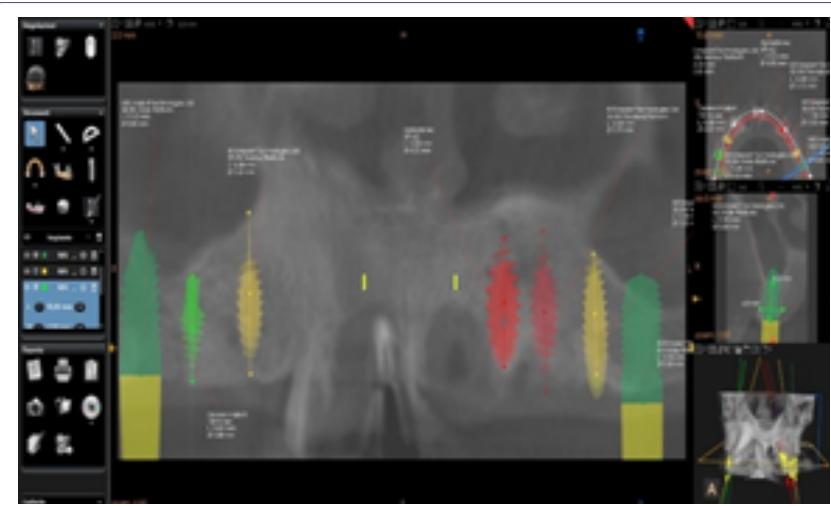

Figure 3: Dental scan showing severe bone resorption.

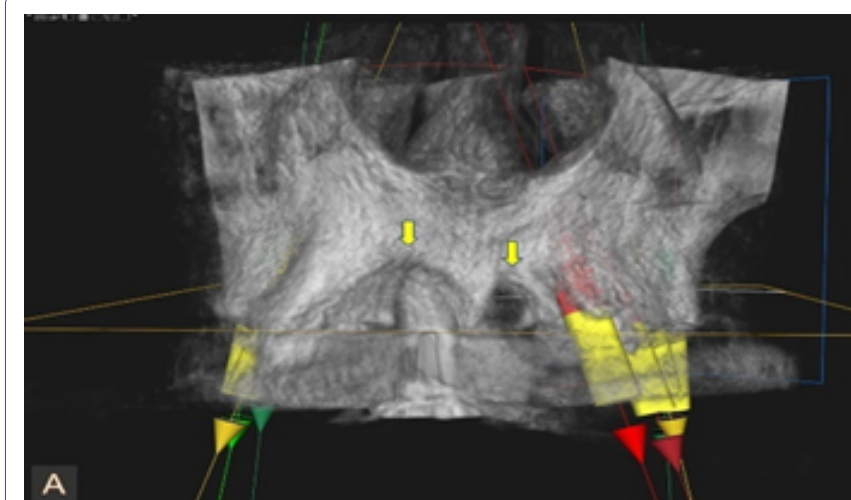

Figure 4: Dental scan showing severe bone resorption.

\section{Clinical Case}

A 49-year-old female patient with unremarkable medical history, presented with the chief complaint of upper loose fixed prosthesis which she has been wearing for many years and gum recessions on lateral incisors which caused the patient social issues. Patient also reported that this situation was causing her working issues because she felt self-consciousness talking or smiling in front of other people.

An Orthopantomogram (OPG) and a Dental Scan were taken (Figures 5-8).

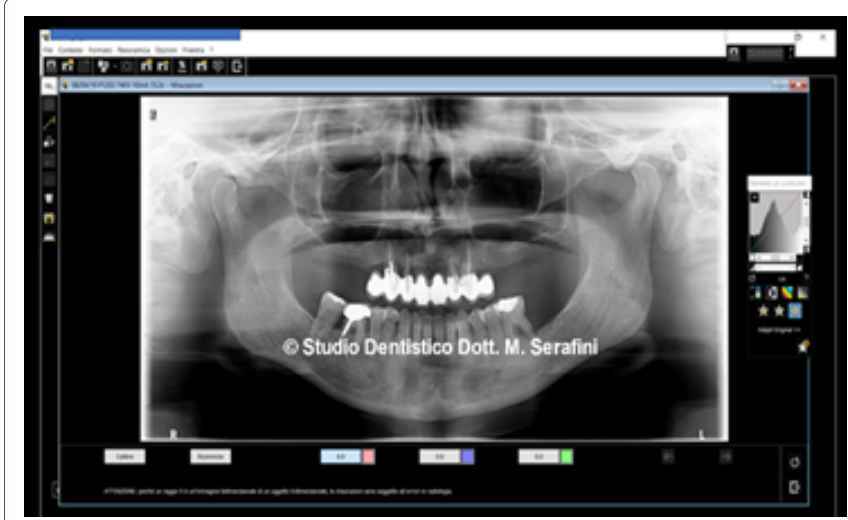

Figure 5: Orthopantomogram.

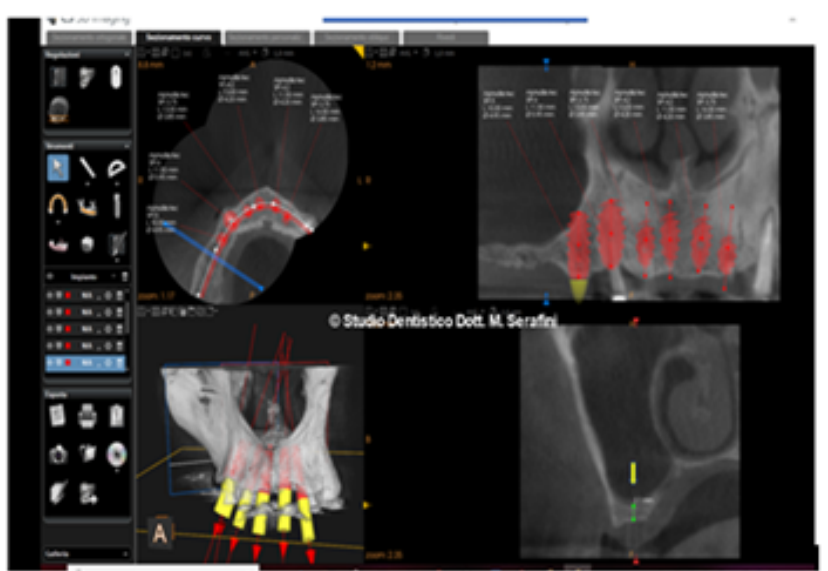

Figure 6: Dental scan. 
Citation: Serafini M, Teodoro SD, Romondio L, Zagaria L (2021) Upper Full Rehabilitation with One to One Immediate Loading Implants: A Case Report. J Stem Cell Res Dev Ther 7: 084.

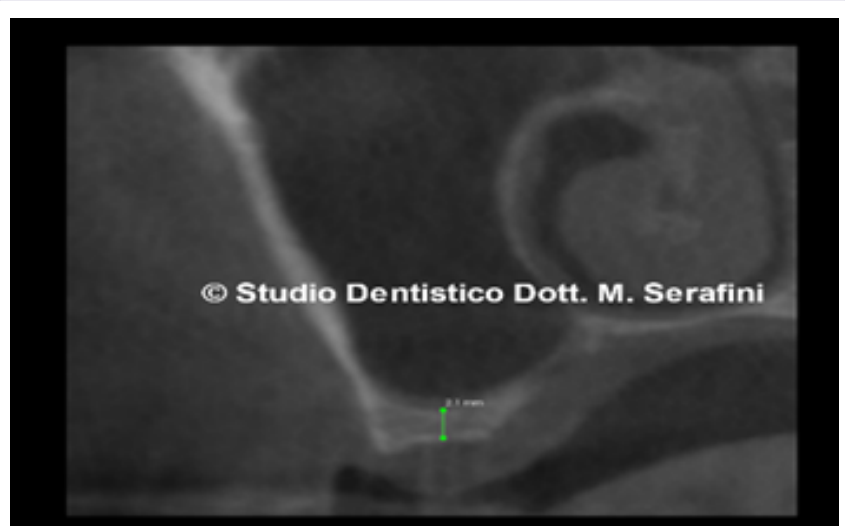

Figure 7: Right side.

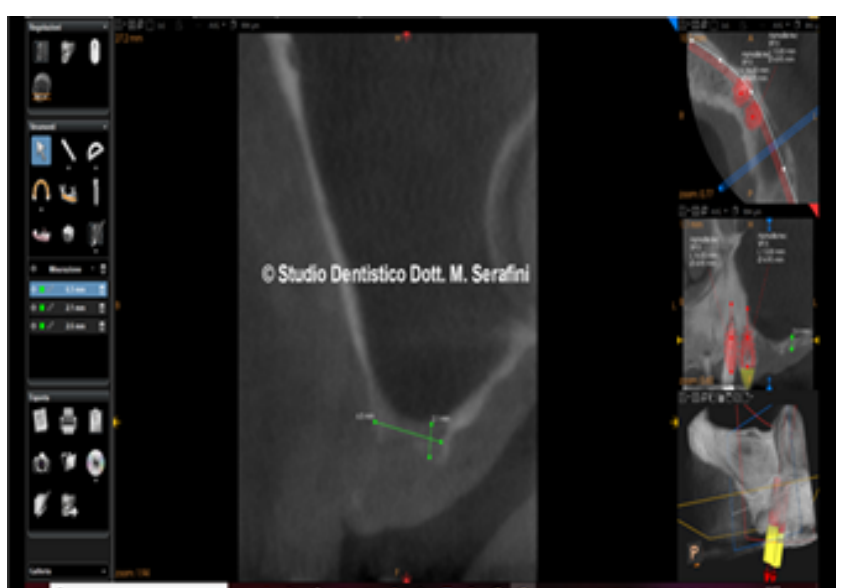

Figure 8: Left side.

Radiographic images show severe bone loss with $2 \mathrm{~mm}$ bone height on both sides.

Accordingly with the patient the treatment plan is extractions of all upper teeth which are no longer restorable and replace the old prosthesis with an immediate loading implant supported one to one.

Prior to surgery patient was prescribed antibiotic therapy (Amoxicillin and Clavulanic acid $1 \mathrm{~g}$, two times a day for one week).

After removal of the old prosthesis the clinical situation is the one showed in figure 9 .

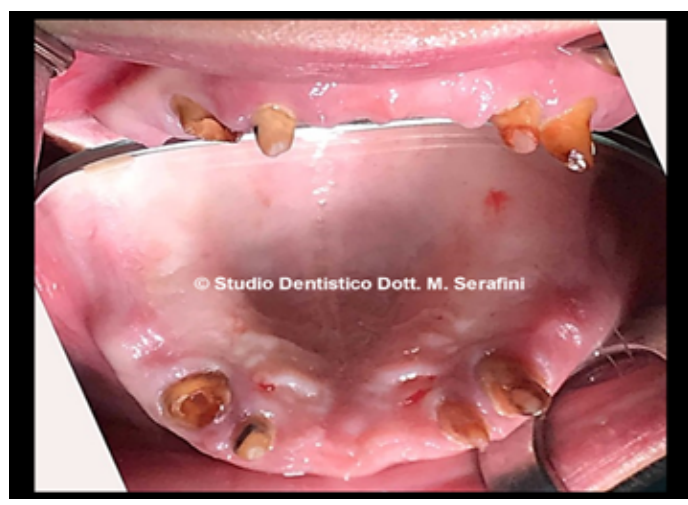

Figure 9: Clinical situation.
6 venous blood tubes samples of $3.5 \mathrm{ml}$ each are taken and centrifuged with sodium citrate as anticoagulant for 20 minutes at $100 \mathrm{rpm}$ obtaining PRP (Figures 10 \& 11).

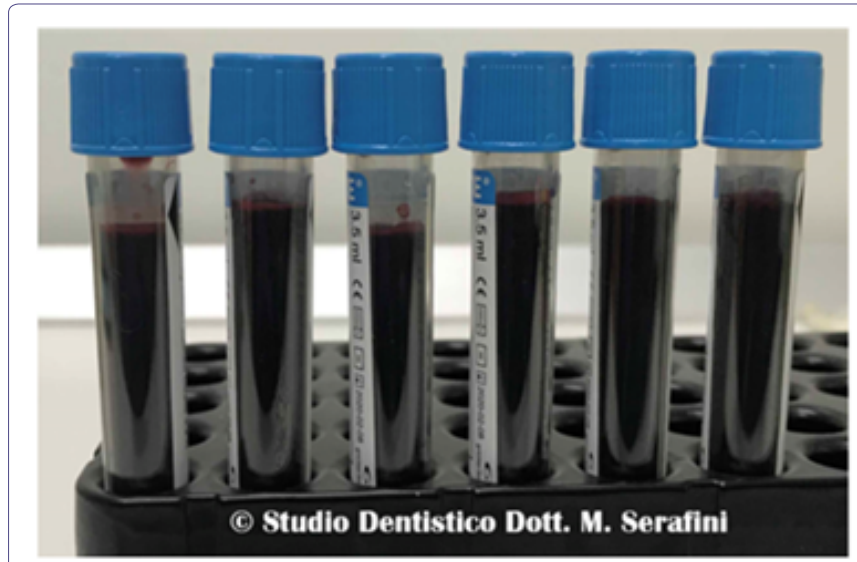

Figure 10: Venous blood.

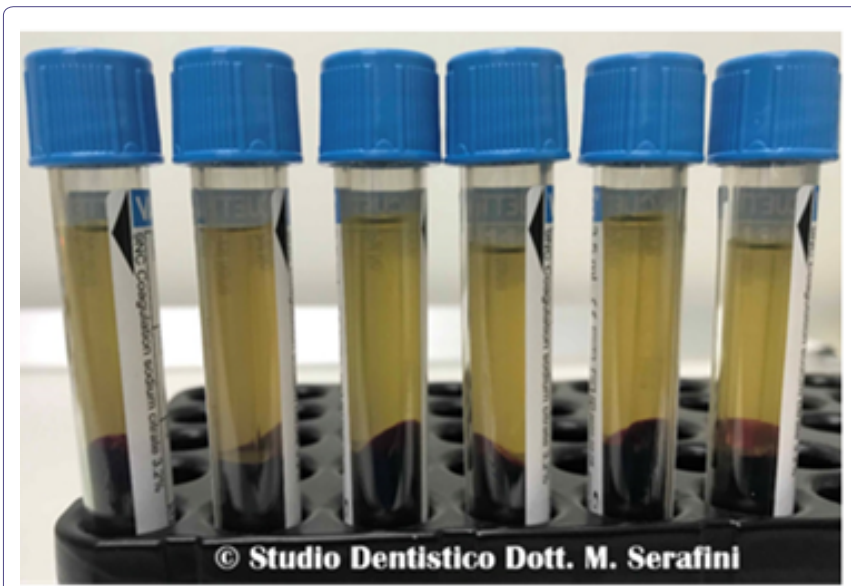

Figure 11: PRP

Under local anesthesia, all upper teeth were extracted, a full thickness flap both palatal and vestibular is reflected and on both sides crestal sinus lift was performed using Crestal Sinus Lift (CSL) implants made by $2 \mathrm{~s}$ implants. A number of 10 implants are inserted, 3 of them submerged and 7 immediately loaded. Autologous bone graft mixed with PRP is inserted as scaffold both palatal and vestibular (Figures 12-16).

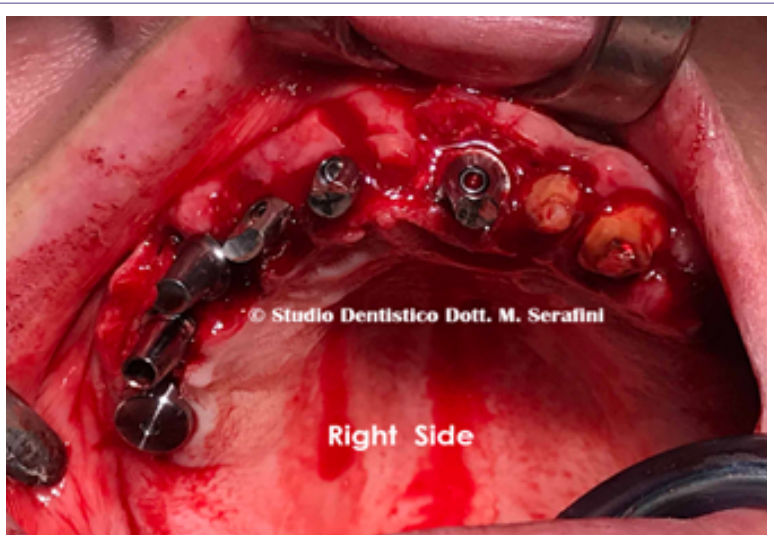

Figure 12: Right side. 
Citation: Serafini M, Teodoro SD, Romondio L, Zagaria L (2021) Upper Full Rehabilitation with One to One Immediate Loading Implants: A Case Report. J Stem Cell Res Dev Ther 7: 084.

- Page 4 of 7 •

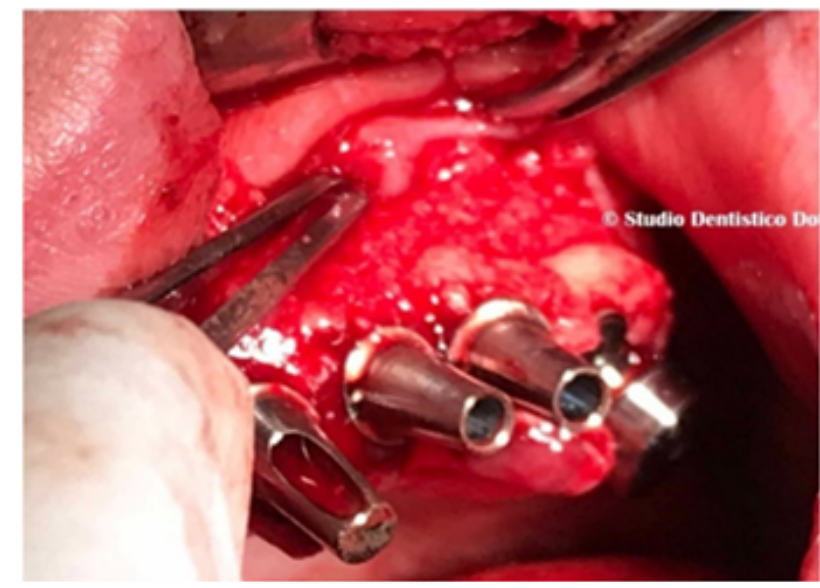

Figure 13: Left side.

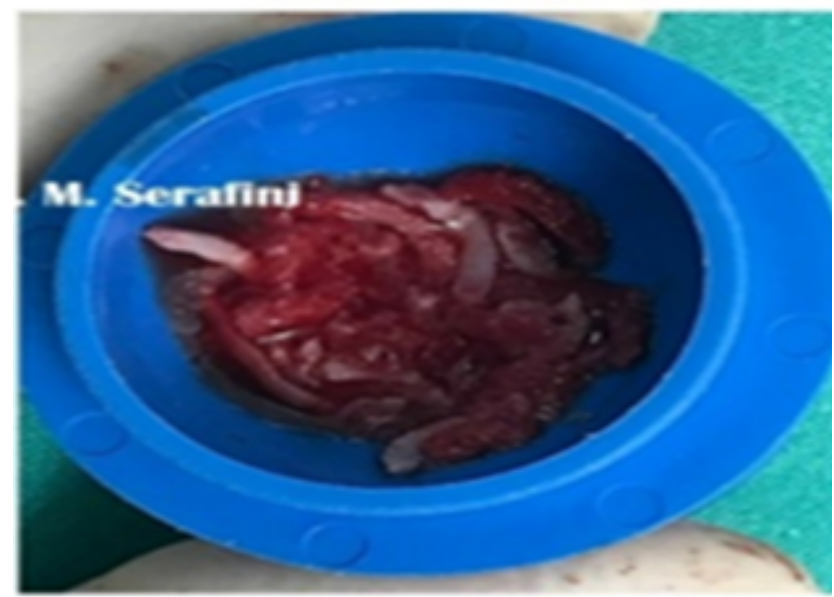

Figure 14: Autologous bone graft.

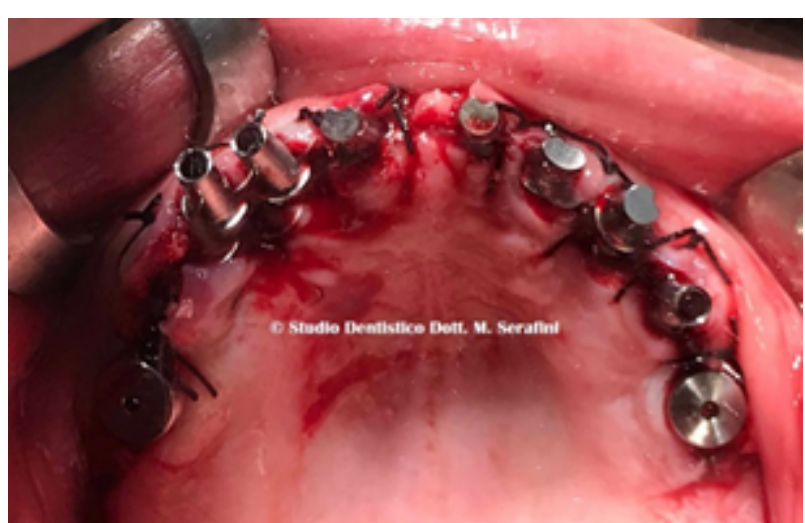

Figure 15: Occlusal view.

Temporary prosthesis is fabricated and placed allowing for proper healing of the soft tissues (Figures 16-18).

After 2 months, accordingly with the patient, it was decided to insert one more implant in position 1.6.

A dental scan was taken to plan the surgery as shown in figures 19 $\& 20$.

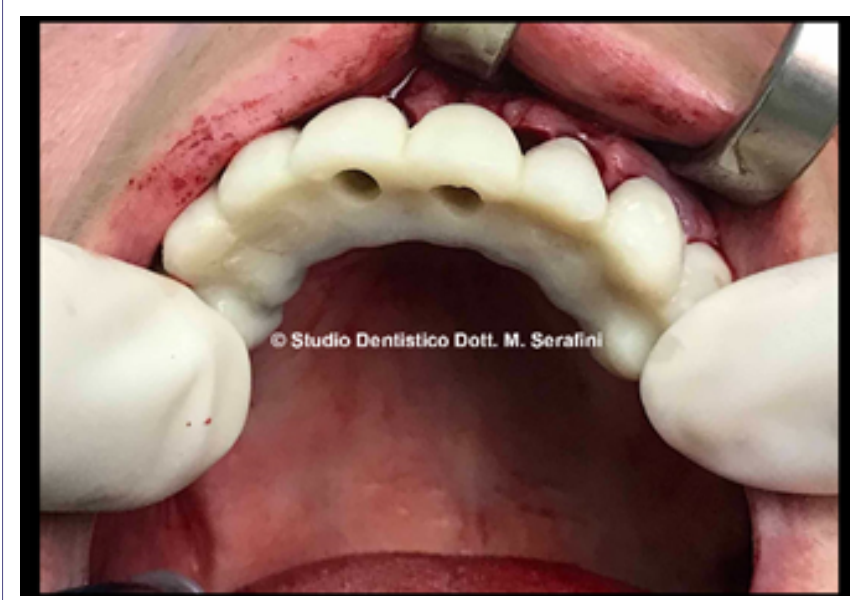

Figure 16: Temporary prosthesis.

Post Surgical Checkup

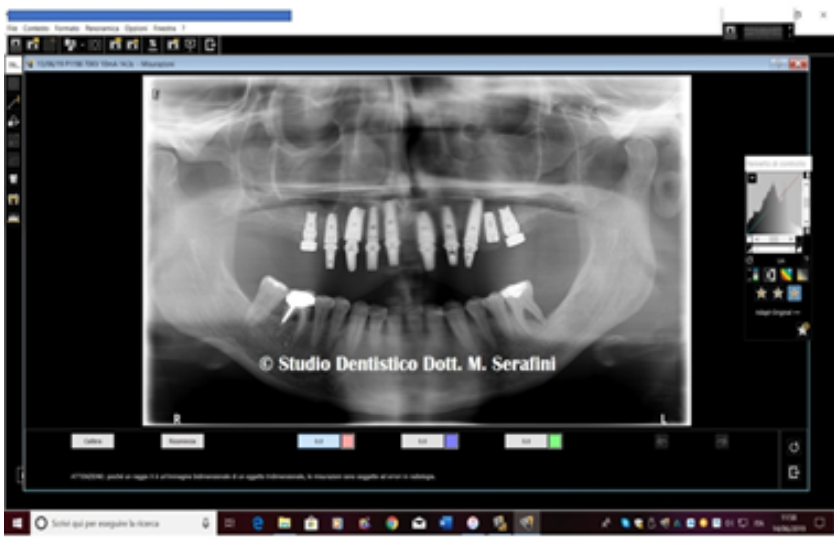

Figure 17: Post-surgical x-ray.

Immediate Loading

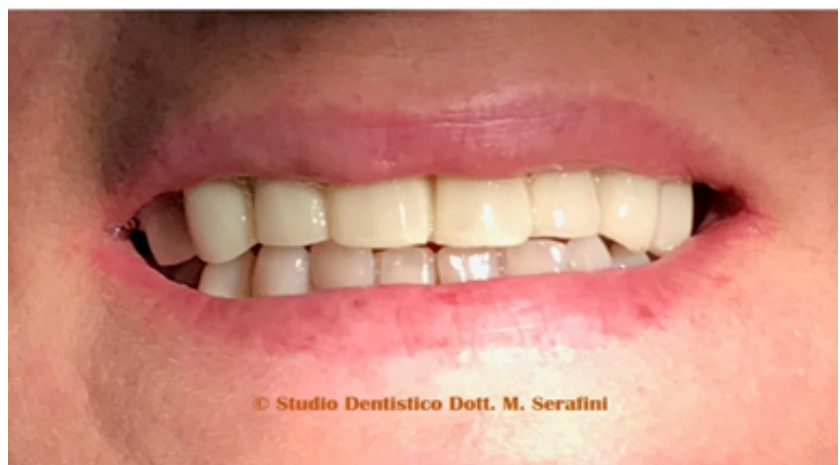

Figure 18: Immediate loading. 
Citation: Serafini M, Teodoro SD, Romondio L, Zagaria L (2021) Upper Full Rehabilitation with One to One Immediate Loading Implants: A Case Report. J Stem Cell Res Dev Ther 7: 084.

- Page 5 of 7 •

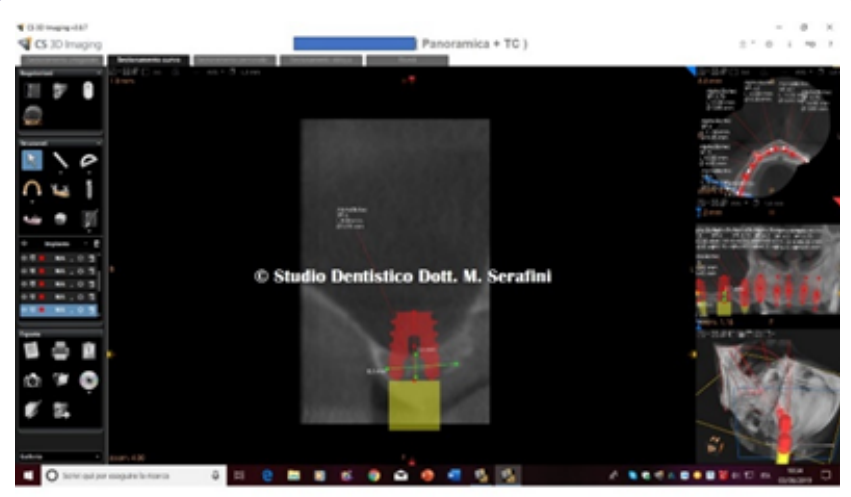

Figure 19: Dental scan.

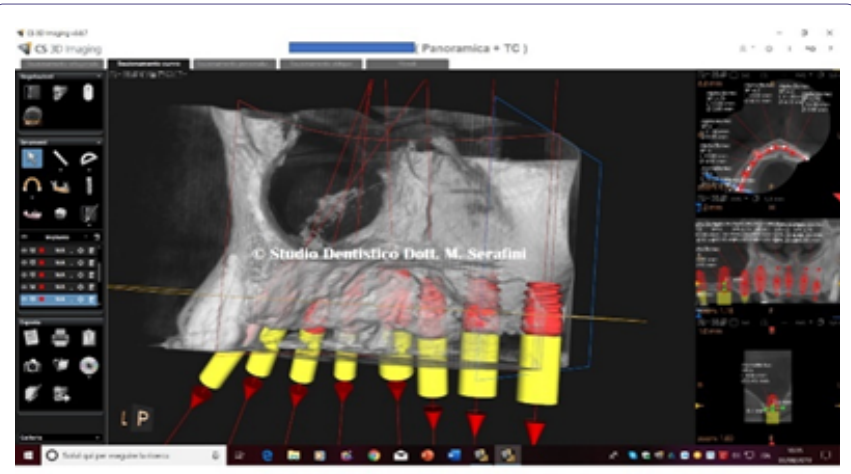

Figure 20: Planning.

6 venous blood test tubes samples were taken to obtain PRP (Figure 21).

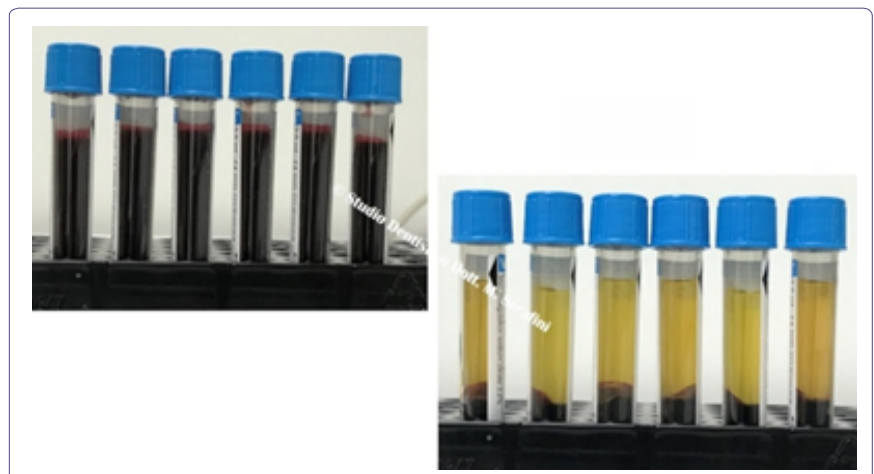

Figure 21: Venous blood and PRP

Under local anesthesia a full thickness flap is reflected palatal and vestibular (Figures $22 \& 23$ ).

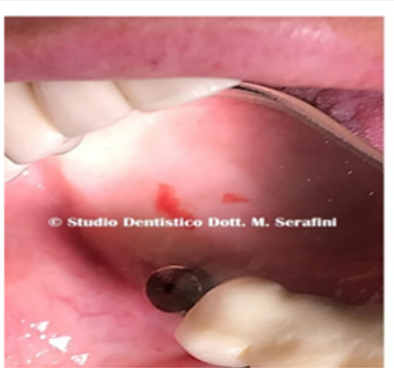

Figure 22: Occlusal view.

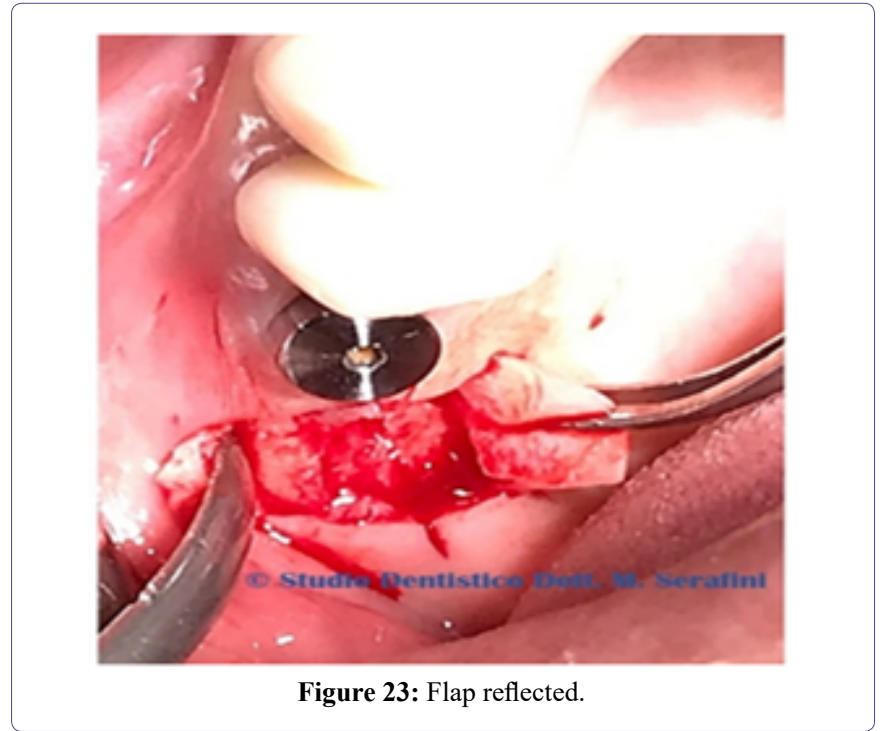

sinus lift trough C.S.L. 2s Implant is performed by placing P.R.P. and a mix of imbibed fibrin sponges and PRF obtained mixing PRP with calcium gluconate as shown in figures $24 \& 25$.

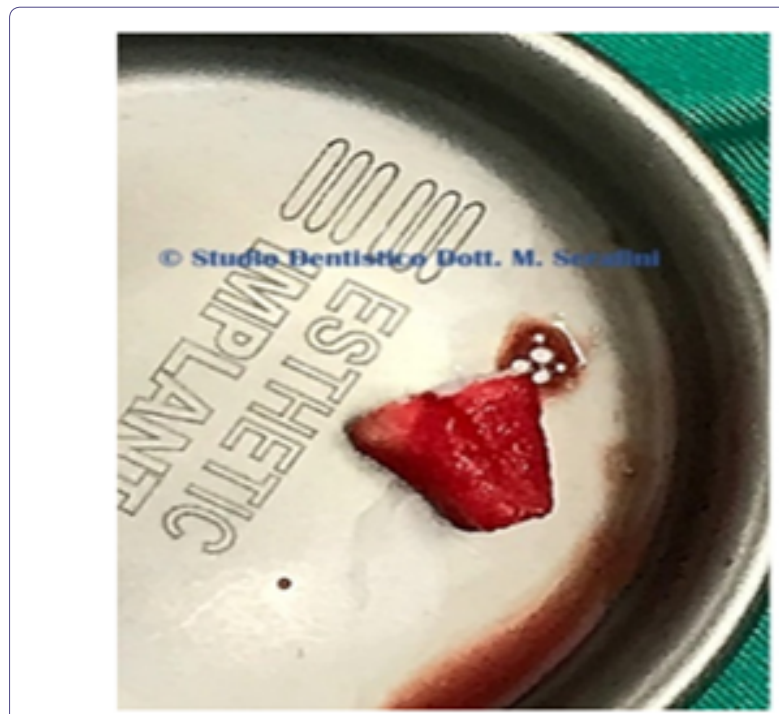

Figure 24: Fibrine sponges mixed with PRF.

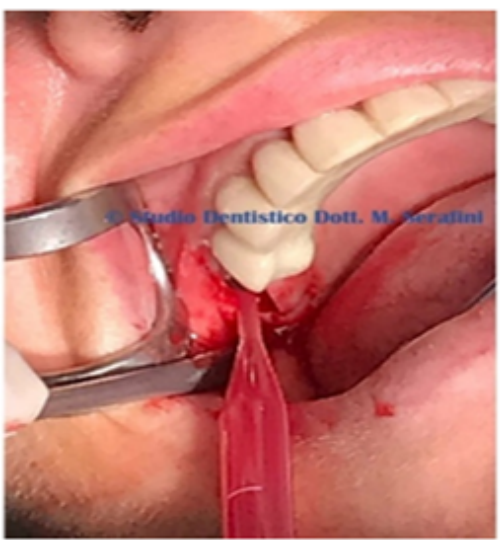

Figure 25: Fibrine sponges mixed with PRF. 
Citation: Serafini M, Teodoro SD, Romondio L, Zagaria L (2021) Upper Full Rehabilitation with One to One Immediate Loading Implants: A Case Report. J Stem Cell Res Dev Ther 7: 084.

-Page 6 of 7 •

Implant positioned showed in figures $26 \& 27$.

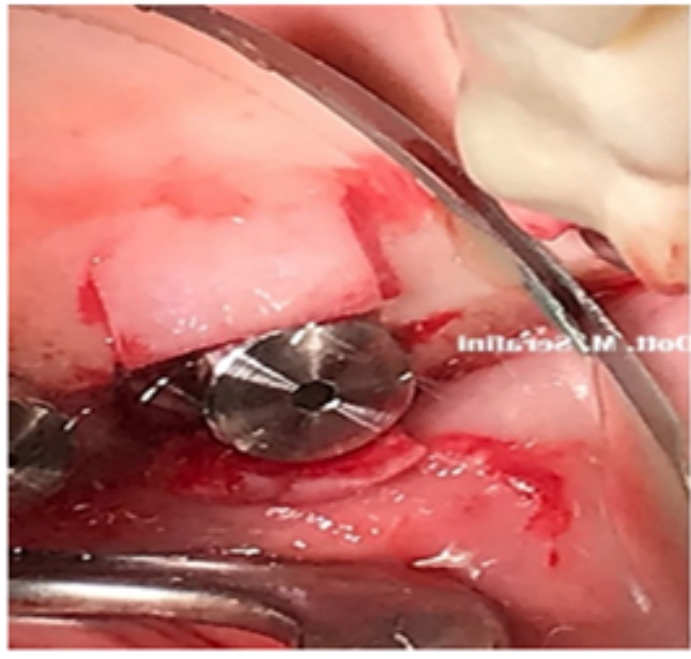

Figure 26: Implant positioned in position 1.6.

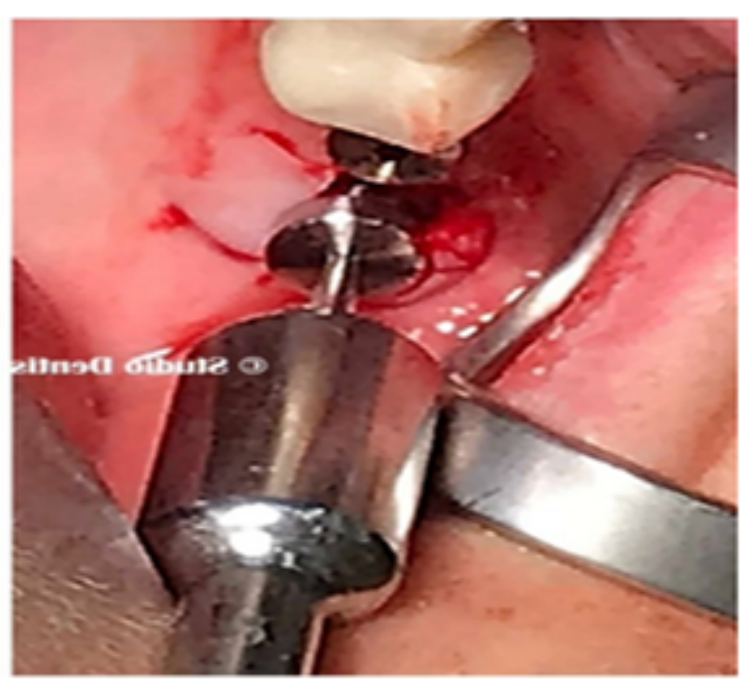

Figure 27: Implant positioned in position 1.6.

Post-surgical checkup is shown in figure 28.

\section{Post Surgical Checkup for 1.6 and 50 days for Others}

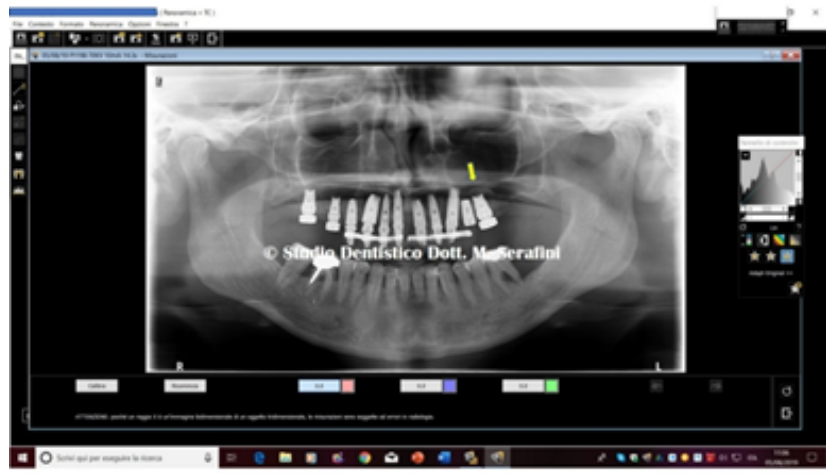

Figure 28: X-ray checkup.
50 days checkup in figure 26 shows a great amount of autologous bone regenerated on the left side pointed out by the yellow arrow in figure 29 .

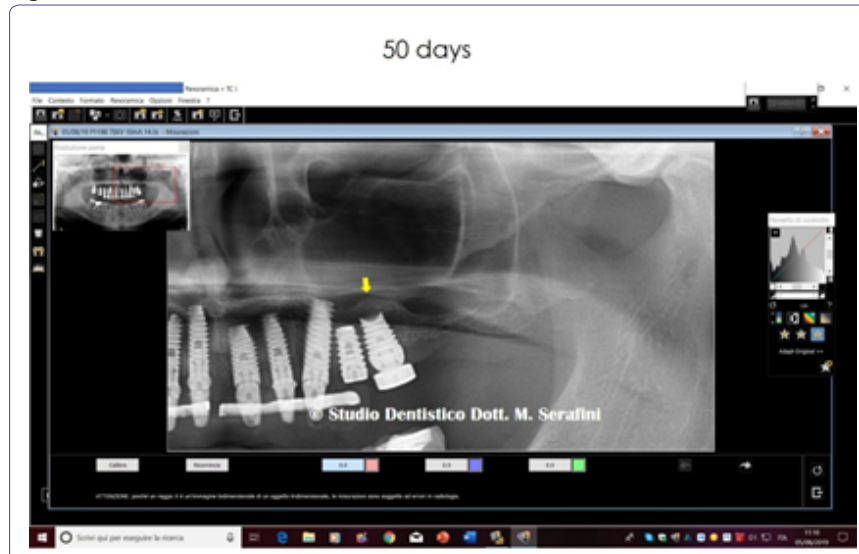

Figure 29: Particular on bone formed after 50 days.

X-ray control after 6 months for the left side and 5 months for the right side in figure 30 shows the sinus floor prior surgery pointed out with red arrow and the bone generated after surgery pointed out with yellow arrows

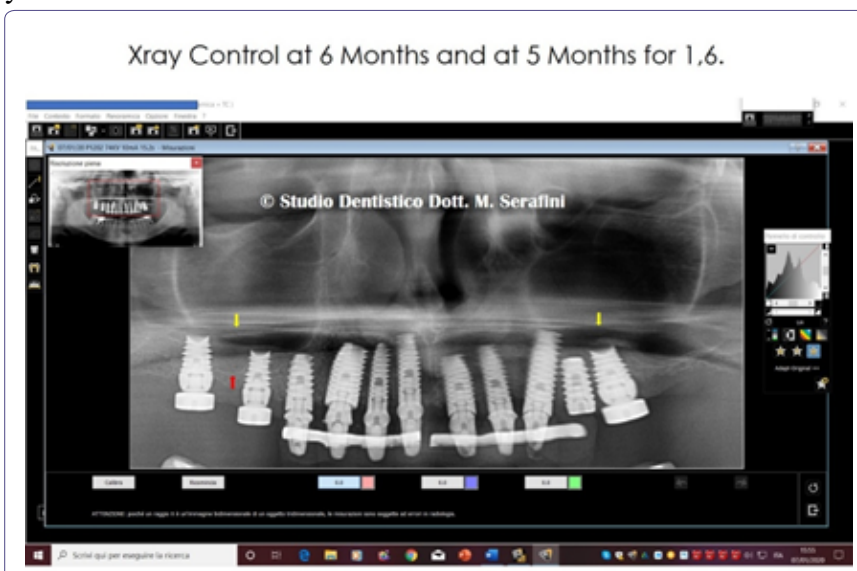

Figure 30: X-ray checkup.

After 1 year for 1.6 and 14 months for 2.6 another X-ray is taken together with a clinical picture (Figures $31 \& 32$ ).

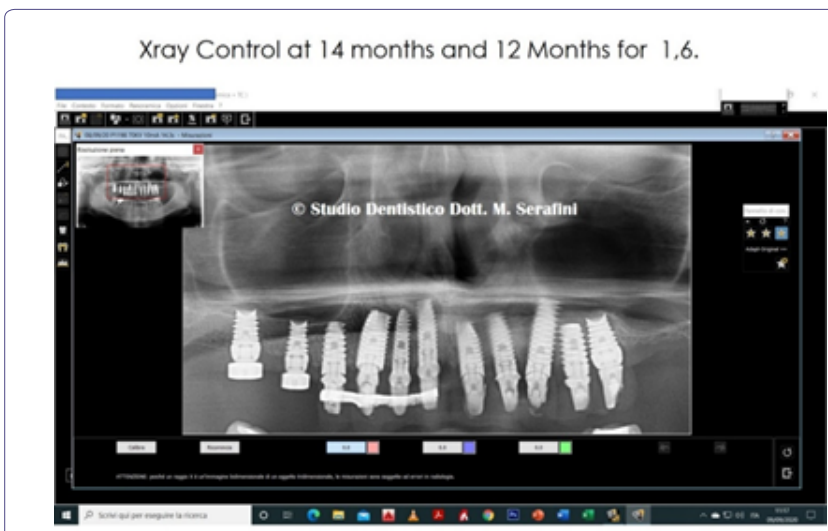

Figure 31: X-ray control. 
Citation: Serafini M, Teodoro SD, Romondio L, Zagaria L (2021) Upper Full Rehabilitation with One to One Immediate Loading Implants: A Case Report. J Stem Cell Res Dev Ther 7: 084.

- Page 7 of 7 •

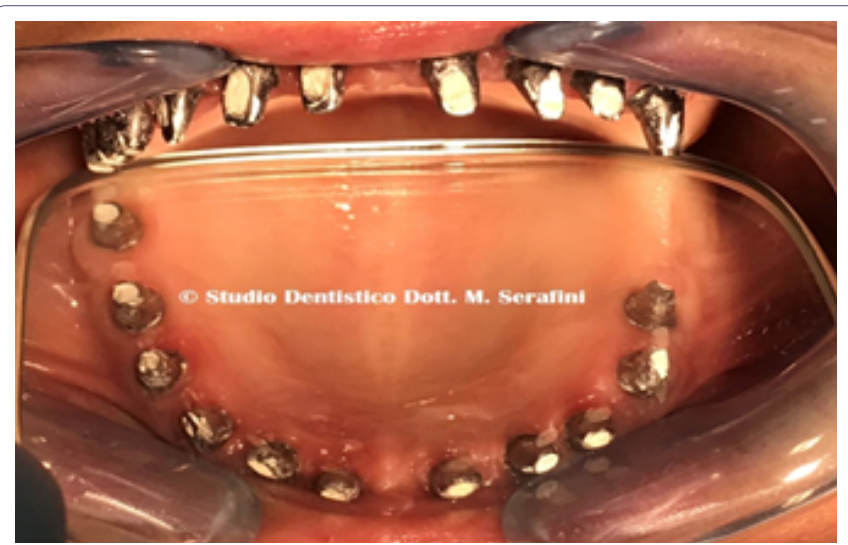

Figure 32: Clinical checkup.

Final prosthesis is made and shown in figures 33-35.

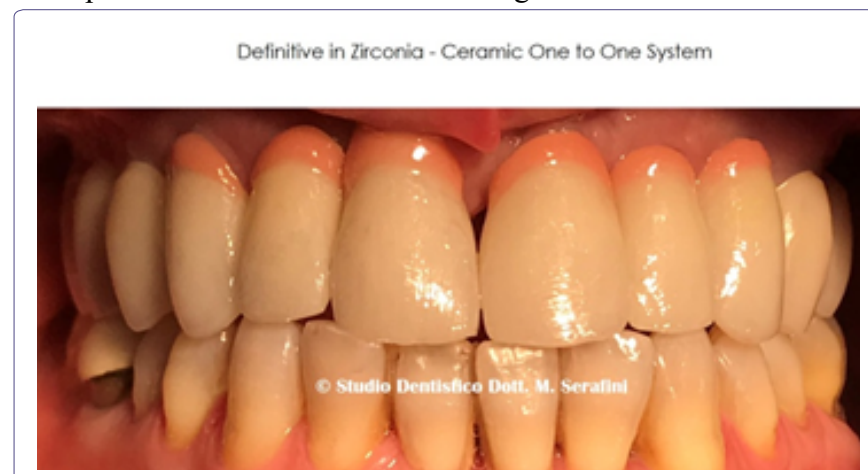

Figure 33: Final outcome.

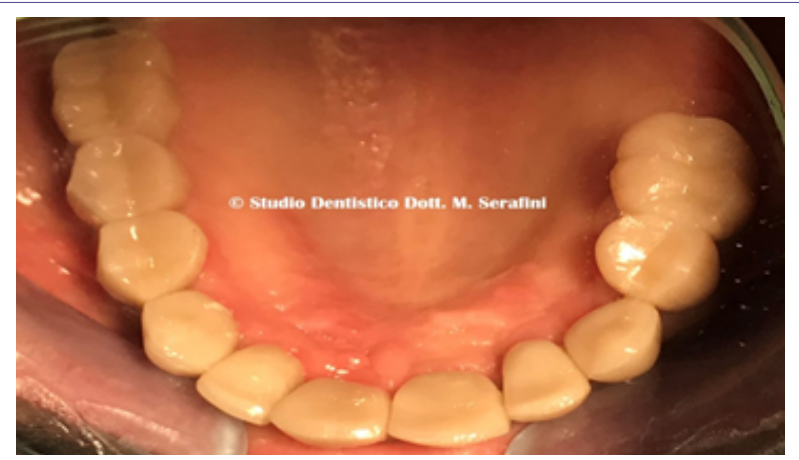

Figure 34: Occlusal view.

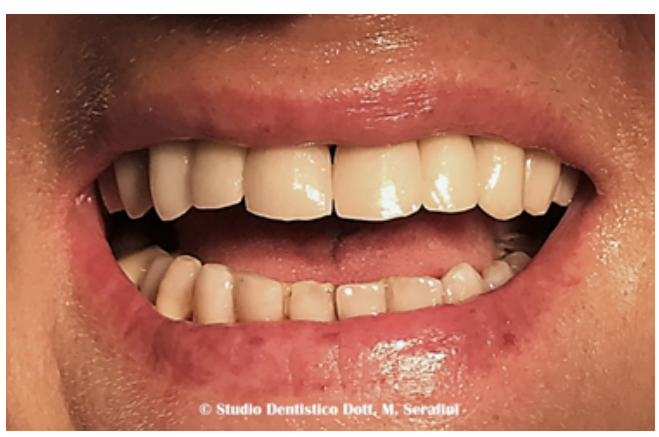

Figure 35: Final outcome.

\section{Discussion}

Successful immediate loading dental implant has been reported as early as 1979. Many are the variables to take into consideration when choosing immediate loading implants rehabilitation, such as primary stability as the key requirement for its success. The torque range of implant insertion is from 30 to $45 \mathrm{Ncm}$, otherwise implants shouldn't be loaded. Another important variable is the prosthetic design which has to ensure a uniform load distribution [5-7], this is why one to one is the prosthetic choice to ensure even forces on each implant inserted and avoid overload issues. Bone type is another criteria to evaluate for a successful outcome. Compact bone gives good primary stability while cancellous bone doesn't. To facilitate stability in softer bone type, implants features such as the ones of C.L.S. $2 \mathrm{~s}$ implant used in the current paper, come in clinician's need.

Of course the success of any clinical procedures begins and ends with the selection of the right patient who has to be skilled to understand not only the treatment and its outcomes, but also the importance of frequent checkups and good maintenance at home.

\section{Conclusion}

The present case report demonstrates how dentistry can change lives. It also shows how we can satisfied patient's needs by providing predictable, long lasting rehabilitation in less time. When executed precisely, using adequate criteria to evaluate the patient, choosing the implant and perform the surgical and prosthetic treatment, a successful outcome can be achieved.

Further studies are necessary to evaluate long term data of immediate loading implants especially in poor bone quality and quantity and in those cases who need bone regeneration like the one described in the present study.

\section{References}

1. Esposito M, Grusovin MG, Willings M, Coulthard P, Worthington HV (2007) Interventions for replacing missing teeth: different times for loading dental implants. Cochrane database Syst Rev 18: CD003878.

2. Romanos Ge, Testori T, Degidi M, Piattelli A (2005) Histologic and histomorphometric findings from retrieved, immediately occlusally loaded implants in humans. J Periodontol 76: 1823-1832.

3. Gallucci GO, Morton D, Weber HP (2009) Loading protocols for dental implants in edentulous patients. Int J Oral Maxillofac Implants 24: 132146 .

4. Serafini M (2021) New Concept of Maxillary Sinus Lift through a New Implant Dedicated: "2s Implant”. J Stem Cell Res Dev Ther 7: 061.

5. Grunder U (2001) Immediate functional loading of immediate implants in edentulous arches; two years result. Int J Periodontics Restorative Dent 21: 545-551.

6. Tealdo T, Bevilacqua M, Menini M, Pera F, Ravera G, et al. (2001) Immediate versus delayed loading of dental implants in edentulous maxillae: a 36-month prospective study. Int J Prosthodont 24: 294-302.

7. Pieri F, Aldini NN, Fini M, Corinaldesi G (2009) Immediate occlusal loading of immediately placed implants supporting fixed restorations in completely edentulous arches: a 1-year prospective pilot study. J Periodontol 80: 411-421. 


\section{H}

Advances In Industrial Biotechnology | ISSN: 2639-5665

Advances In Microbiology Research | ISSN: 2689-694X

Archives Of Surgery And Surgical Education | ISSN: 2689-3126

Archives Of Urology

Archives Of Zoological Studies | ISSN: 2640-7779

Current Trends Medical And Biological Engineering

International Journal Of Case Reports And Therapeutic Studies | ISSN: 2689-310X

Journal Of Addiction \& Addictive Disorders | ISSN: 2578-7276

Journal Of Agronomy \& Agricultural Science | ISSN: 2689-8292

Journal Of AIDS Clinical Research \& STDs | ISSN: 2572-7370

Journal Of Alcoholism Drug Abuse \& Substance Dependence | ISSN: 2572-9594

Journal Of Allergy Disorders \& Therapy | ISSN: 2470-749X

Journal Of Alternative Complementary \& Integrative Medicine | ISSN: 2470-7562

Journal Of Alzheimers \& Neurodegenerative Diseases | ISSN: 2572-9608

Journal Of Anesthesia \& Clinical Care | ISSN: 2378-8879

Journal Of Angiology \& Vascular Surgery | ISSN: 2572-7397

Journal Of Animal Research \& Veterinary Science | ISSN: 2639-375

Journal Of Aquaculture \& Fisheries | ISSN: 2576-5523

Journal Of Atmospheric \& Earth Sciences | ISSN: 2689-8780

Journal Of Biotech Research \& Biochemistry

Journal Of Brain \& Neuroscience Research

Journal Of Cancer Biology \& Treatment | ISSN: 2470-7546

Journal Of Cardiology Study \& Research | ISSN: 2640-768X

Journal Of Cell Biology \& Cell Metabolism | ISSN: 2381-1943

Journal Of Clinical Dermatology \& Therapy | ISSN: 2378-8771

Journal Of Clinical Immunology \& Immunotherapy | ISSN: 2378-8844

Journal Of Clinical Studies \& Medical Case Reports | ISSN: 2378-880

Journal Of Community Medicine \& Public Health Care | ISSN: 2381-1978

Journal Of Cytology \& Tissue Biology | ISSN: 2378-9107

Journal Of Dairy Research \& Technology | ISSN: 2688-9315

Journal Of Dentistry Oral Health \& Cosmesis | ISSN: 2473-6783

Journal Of Diabetes \& Metabolic Disorders | ISSN: 2381-201X

Journal Of Emergency Medicine Trauma \& Surgical Care | ISSN: 2378-8798

Journal Of Environmental Science Current Research | ISSN: 2643-5020

Journal Of Food Science \& Nutrition | ISSN: 2470-1076

Journal Of Forensic Legal \& Investigative Sciences | ISSN: 2473-733X

Journal Of Gastroenterology \& Hepatology Research | ISSN: 2574-2566
Journal Of Genetics \& Genomic Sciences | ISSN: 2574-2485

Journal Of Gerontology \& Geriatric Medicine | ISSN: 2381-8662

Journal Of Hematology Blood Transfusion \& Disorders | ISSN: 2572-2999

Journal Of Hospice \& Palliative Medical Care

Journal Of Human Endocrinology | ISSN: 2572-9640

Journal Of Infectious \& Non Infectious Diseases | ISSN: 2381-8654

Journal Of Internal Medicine \& Primary Healthcare | ISSN: 2574-2493

Journal Of Light \& Laser Current Trends

Journal Of Medicine Study \& Research | ISSN: 2639-5657

Journal Of Modern Chemical Sciences

Journal Of Nanotechnology Nanomedicine \& Nanobiotechnology | ISSN: 2381-2044

Journal Of Neonatology \& Clinical Pediatrics | ISSN: 2378-878X

Journal Of Nephrology \& Renal Therapy | ISSN: 2473-7313

Journal Of Non Invasive Vascular Investigation | ISSN: 2572-7400

Journal Of Nuclear Medicine Radiology \& Radiation Therapy | ISSN: 2572-7419

Journal Of Obesity \& Weight Loss | ISSN: 2473-7372

Journal Of Ophthalmology \& Clinical Research | ISSN: 2378-8887

Journal Of Orthopedic Research \& Physiotherapy | ISSN: 2381-2052

Journal Of Otolaryngology Head \& Neck Surgery | ISSN: 2573-010X

Journal Of Pathology Clinical \& Medical Research

Journal Of Pharmacology Pharmaceutics \& Pharmacovigilance | ISSN: 2639-5649

Journal Of Physical Medicine Rehabilitation \& Disabilities | ISSN: 2381-8670

Journal Of Plant Science Current Research | ISSN: 2639-3743

Journal Of Practical \& Professional Nursing | ISSN: 2639-568

Journal Of Protein Research \& Bioinformatics

Journal Of Psychiatry Depression \& Anxiety | ISSN: 2573-0150

Journal Of Pulmonary Medicine \& Respiratory Research | ISSN: 2573-0177

Journal Of Reproductive Medicine Gynaecology \& Obstetrics | ISSN: 2574-2574

Journal Of Stem Cells Research Development \& Therapy | ISSN: 2381-2060

Journal Of Surgery Current Trends \& Innovations | ISSN: 2578-7284

Journal Of Toxicology Current Research | ISSN: 2639-3735

Journal Of Translational Science And Research

Journal Of Vaccines Research \& Vaccination | ISSN: 2573-0193

Journal Of Virology \& Antivirals

Sports Medicine And Injury Care Journal | ISSN: 2689-8829

Trends In Anatomy \& Physiology | ISSN: 2640-7752

Submit Your Manuscript: https://www.heraldopenaccess.us/submit-manuscript 